\title{
Effect of Hot Isostatic Pressing and Powder Feedstock on Porosity, Microstructure, and Mechanical Properties of Selective Laser Melted AlSi10Mg
}

\author{
Christopher B. Finfrock ${ }^{1} \cdot$ Andrea Exil $^{2} \cdot$ Jay D. Carroll ${ }^{2} \cdot$ Lisa Deibler $^{1}$
}

Received: 12 March 2018/Revised: 7 May 2018 / Accepted: 21 May 2018/Published online: 6 June 2018

(C) Springer Science+Business Media, LLC, part of Springer Nature and ASM International 2018

\begin{abstract}
AlSi10Mg tensile bars were additively manufactured using the powder-bed selective laser melting process. Samples were subjected to stress relief annealing and hot isostatic pressing. Tensile samples built using fresh, stored, and reused powder feedstock were characterized for microstructure, porosity, and mechanical properties. Fresh powder exhibited the best mechanical properties and lowest porosity while stored and reused powder exhibited inferior mechanical properties and higher porosity. The microstructure of stress relieved samples was fine and exhibited (001) texture in the z-build direction. Microstructure for hot isostatic pressed samples was coarsened with fainter (001) texture. To investigate surface and interior defects, scanning electron microscopy, optical fractography, and laser scanning microscopy techniques were employed. Hot isostatic pressing eliminated internal pores and reduced the size of surface porosity associated with the selective laser melting process. Hot isostatic pressing tended to increase ductility at the expense of decreasing strength. However, scatter in ductility of hot isostatic pressed parts suggests that the presence of unclosed surface porosity facilitated fracture with crack propagation inward from the surface of the part.
\end{abstract}

Keywords Aluminum alloys · Additive manufacturing $\cdot$ Fractography $\cdot$ Mechanical behavior $\cdot$ Microstructure

\section{Introduction}

Additive manufacturing is a flexible method for fabrication of complex metallic components. Selective laser melting (SLM) is a technique by which a laser selectively melts a bed of metal powder. Layers of melted metal are deposited successively resulting in near-net-shape parts [1]. The rapid cooling of these layers results in a non-equilibrium state with very fine microstructure and significant residual stress. This microstructure can lead to unique mechanical properties such as high hardness and fatigue resistance as well as unique thermal properties [2].

Christopher B. Finfrock

cfinfro@sandia.gov

1 Metallurgy and Materials Joining, Sandia National Laboratories, Albuquerque, NM 87185, USA

2 Materials and Mechanics and Tribology, Sandia National Laboratories, Albuquerque, NM 87185, USA
$\mathrm{AlSi} 10 \mathrm{Mg}$ is a hypoeutectic aluminum-silicon-magnesium alloy regarded for its light weight, low melting point and ability to be solid solution strengthened by its alloying elements. The alloy's low melting point and strengthening characteristics make it an appealing candidate for high solidification rate processing techniques including additive manufacturing. Understanding the microstructure evolution of additive manufactured AlSi10Mg is critical for predicting mechanical performance due to the alloy's solution strengthening mechanisms; if large volume fractions of second phases rich in silicon and magnesium form during heat treatment, then it is likely that the strength will be reduced because the contribution of solid solution strengthening will be decreased. The as-solidified microstructure of selective laser melted $\mathrm{AlSi} 10 \mathrm{Mg}$ is columnar with silicon enriched intercolumnar regions. Intercolumnar spacing is dependent on cooling rate, with typical spacing around $1 \mu \mathrm{m}$ [2-4]. The as-solidified grain structure is relatively fine. According to Yang, as-solidified grains exhibited $13 \mu \mathrm{m}$ width and $44 \mu \mathrm{m}$ length parallel to the build direction. When annealed for $15 \mathrm{~min}$ at $450{ }^{\circ} \mathrm{C}$, 
the grains coarsened to an average width of $16 \mu \mathrm{m}$ and length of $64 \mu \mathrm{m}$ [2].

Depending on the powder feedstock, SLM machine parameters and environmental factors, the SLM process often introduces porosity into parts. Several forms of porosity are common. Lack of fusion pores are formed due to inclusions in the powder feedstock and error in SLM hatching parameters [5]. Spherical gas pores are formed due to entrapped gases in the aluminum liquid layer [6]. Keyhole porosity occurs due to evaporation of the liquid aluminum and is associated with a high aspect ratio melt pool [7]. Additionally, preexisting pores present in the powder feedstock can move to the additive deposit [8]. In this study, lack of fusion pores and gas pores are accessed to be the two predominant pores present. The keyhole porosity mode was eliminated on the basis that the melt pool morphology is inconsistent with the high aspect ratio associated with keyhole porosity. The preexisting pore mode was eliminated after the aluminum powder particles were determined to be solid using metallographic sectioning.

Gas porosity is prominent in SLM AlSi10Mg because aluminum reduces water to liberate hydrogen gas. This hydrogen gas is injected into the melt pool. The solubility of hydrogen in pure molten aluminum is a mere $14 \mathrm{ppm}$ at solidification and drops as temperature drops [9]. Once a threshold value, which depends on the alloy composition, is reached, porosity will form. Weingarten suggested that the amount of hydrogen observed in an SLM melt of AlSi10Mg exceeded the solubility of hydrogen in liquid pure aluminum by 50 times [10]. To minimize porosity, it is recommended that the powder was stored in an inert environment to decrease oxygen and water bonded to the powder surface. Reusing powder for multiple builds and storing powder in an unsuitable environment may lead to significant porosity. An additional porous crust layer associated with the hatching pattern is common near the surface of SLM parts. The crust layer is permeated with cracks oriented normal to the build direction.

Bulk porosity fraction greater than several percent has been found to detrimentally impact mechanical properties of metallic parts [11-13]. This is often attributed to the fracture path preferentially traveling along regions with high numbers of defects [14]. Contrary to large pores, nanoscale pores have been known to increase strength by impeding the flow of dislocations through the material [15]. Given the broad range of defects in SLM AlSi10Mg including porosity and microstructure anisotropy, it is prudent to understand the impact of these defects on mechanical properties. Boyce and Salzbrenner have taken significant efforts to quantify the mechanical properties of additive manufactured stainless steel and microfabricated materials using extreme value techniques by performing hundreds of tension tests on small tension dogbones [16-19]. Extreme value techniques allow understanding of the weakest-link behavior of flaw-containing materials by illuminating mechanical properties in statistically rare cases. Although others have quantified the mechanical performance of SLM AlSi10Mg in a limited number of parts $[1,20]$, none have reported the high testing volumes needed for analysis of extreme values of ductility and ultimate tensile strength. One goal of this paper is to test a statistically significant quantity of tensile samples to characterize the weakest-link behavior of SLM AlSi10Mg.

A more encompassing goal is to tailor porosity and microstructure to produce concurrently strong and ductile parts. Two methods of thermal processing are investigated: stress relief annealing (SRA) and hot isostatic pressing (HIP). SRA is employed to decrease the internal stress within the as-printed parts. HIP is used to eliminate porosity at the expense of coarsening the microstructure and reducing the strength. In this paper, we investigate the effect of powder feedstock on porosity, microstructure, and mechanical properties. Three powder conditions are considered: fresh, stored, and reused. This paper elucidates the relationships between these variables and provides insight into the mechanics and metallurgical interactions. Results may provide insight about optimizing thermal processing and powder feedstock for adequate and consistent mechanical properties.

\section{Experimental Procedure}

Dogbone tensile specimens were fabricated using AlSi10Mg powder purchased from LPW Technology Ltd [21]. Tensile specimens had a cross section of 1.5 by $2.5 \mathrm{~mm}$ and a gauge length of $10 \mathrm{~mm}$ as shown in Fig. 1a. Metallographic characterization was performed on additional tension specimens with a square cross section of $6.25 \mathrm{~mm}$ and a gauge length of $25 \mathrm{~mm}$ as shown in Fig. 1b. Tensile specimens were built adjacent to one another on an aluminum build plate using the SLM process on a Renishaw M250 machine. During printing, a striped hatching strategy was used with $5 \mathrm{~mm}$ stripes and $130 \mu \mathrm{m}$ hatch spacing. Laser power was set at 200 watts, with 130 microsecond exposure time and $70 \mu \mathrm{m}$ spot diameter. Ultra-high purity (99.999\%) bottled argon was used to sheild the machine to below 100 parts per million oxygen. Identical machine parameters were used for each build because build parameters have been shown to have a large effect on the characteristics of the finished parts.

Samples were printed using three different powder conditions. Fresh powder was used to fabricate the first build plate. Powder that had been stored for several weeks in a nominally argon environment was used to fabricate a 
A
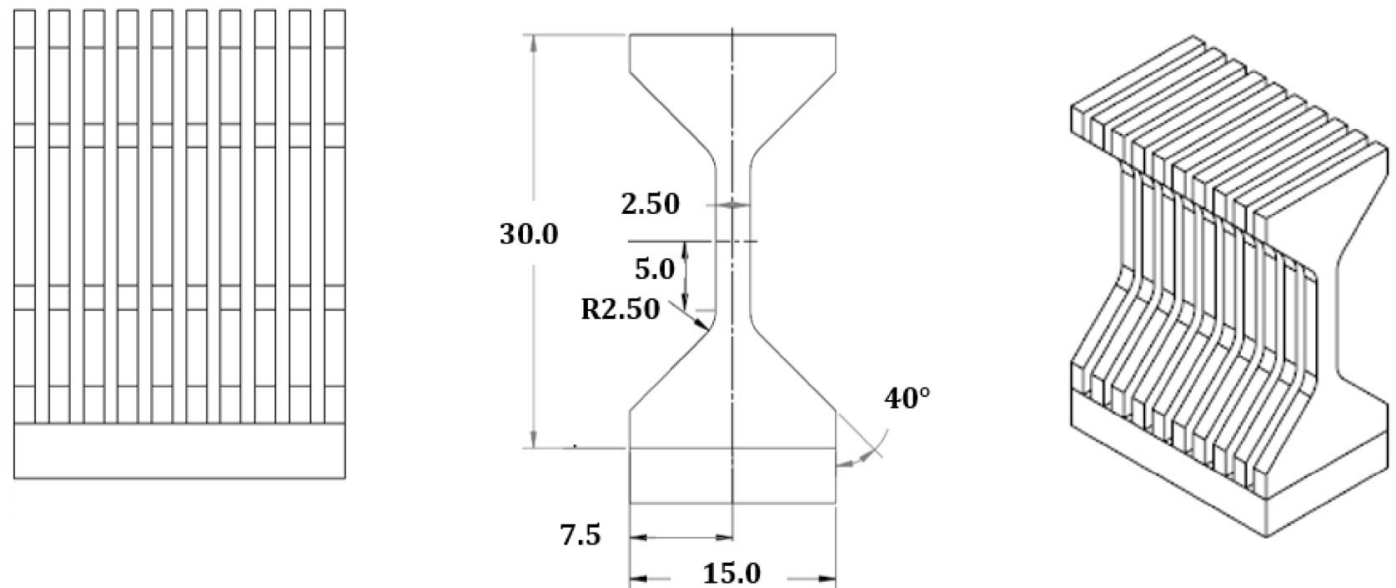

B
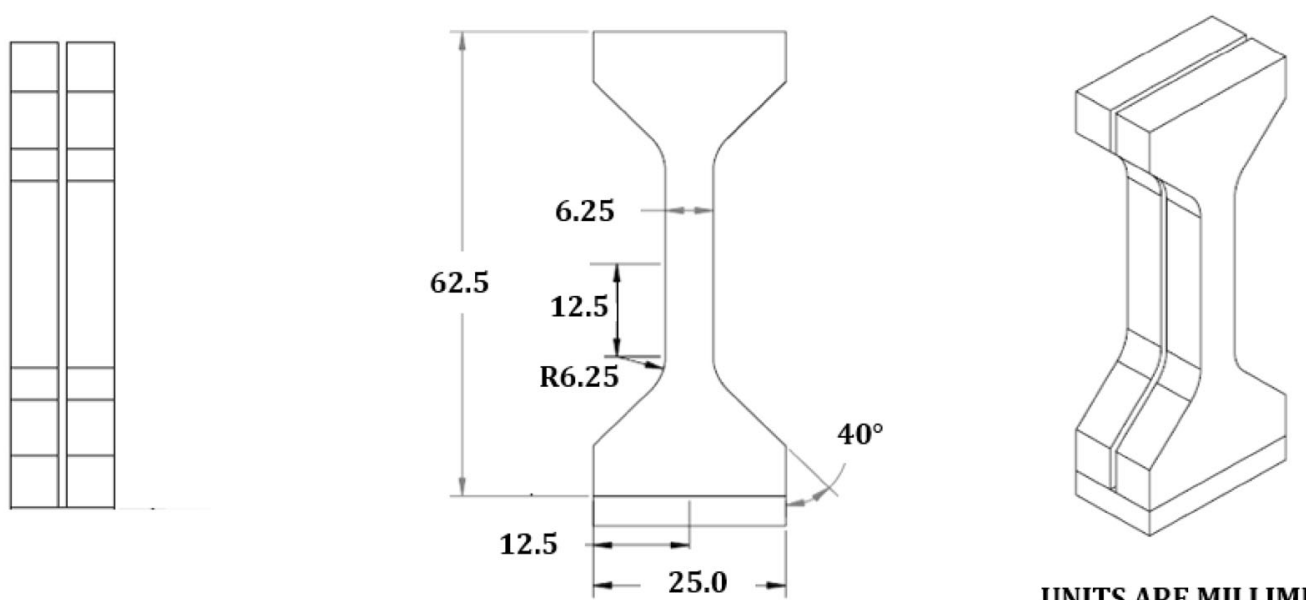

UNITS ARE MILLIMETERS

Fig. 1 (a) $1.5 \times 2.5 \mathrm{~mm}$ dogbone tension specimen used to determine mechanical performance. (b) Additional $6.5 \times 6.5 \mathrm{~mm}$ dogbone tension specimen used for metallographic characterization

second build plate. Powder which was reused from four prior printing operations was used to fabricate a third build plate. While all powder handling and storage was performed under inert gas (argon) in a room where the temperature and humidity were controlled, the dryness of the argon during processing is unknown. For data presentation, powder feedstocks are addressed, respectively, as fresh, stored, and reused. Chemical composition of each powder feedstock was determined by glow discharge mass spectrometry (GD-MS).

After printing, tensile specimens were separated from the build plate by wire electrical discharge machining (EDM). Each tensile specimen's location on the build plate was recorded to determine the impact of location on microstructure and mechanical properties. All samples were subjected to a stress relief annealing heat treatment while attached to the build plate at $300^{\circ} \mathrm{C}$ for $2 \mathrm{~h}$. Stress relieving was performed in a nominally argon environment. All samples, rather than a few selected samples, were stress relieved because stress relief was performed while the samples were attached to the build plate. This simplified workflow considering the large volume of samples. Some samples were hot isostatic pressed after stress relief annealing. The HIP process applied $103 \mathrm{MPa}$ pressure at $521{ }^{\circ} \mathrm{C}$ for $2 \mathrm{~h}$., which has the effect of reshaping the silicon distribution from the silicon-rich intercolumnar regions to spherical particles. Archimedes density technique [22] was used to determine the bulk porosity of the tensile samples before and after HIP.

High throughput tensile testing was performed by employing a process developed by Boyce and Salzbrenner $[17,18]$. Dogbone shaped tensile bars were top-loaded into notched grips then pulled in tension along their build height direction. In this paper, the build height direction (i.e., laser direction) is referred to as the $Z$-direction. Tension samples 
Table 1 Chemical composition (wt.\%) of tensile bars built from each powder type determined by glow discharge mass spectrometry

\begin{tabular}{lllllll}
\hline Powder condition & $\mathrm{Al}$ & $\mathrm{Si}$ & $\mathrm{Mg}$ & $\mathrm{Fe}$ & $\mathrm{Cu}$ & $\mathrm{Ni}$ \\
\hline Nominal composition & $\mathrm{Bal}$ & $9.0-11.0$ & $0.25-0.45$ & $0.25 \mathrm{Max}$ & $0.05 \mathrm{Max}$ & $0.05 \mathrm{Max}$ \\
Fresh powder & 88.31 & 11.04 & 0.34 & 0.12 & 0.04 & 0.03 \\
Partial fresh powder & 88.00 & 11.29 & 0.32 & 0.17 & 0.03 & 0.04 \\
Reused powder & 88.36 & 11.07 & 0.33 & 0.16 & 0.03 & 0.04 \\
\hline
\end{tabular}

SRA
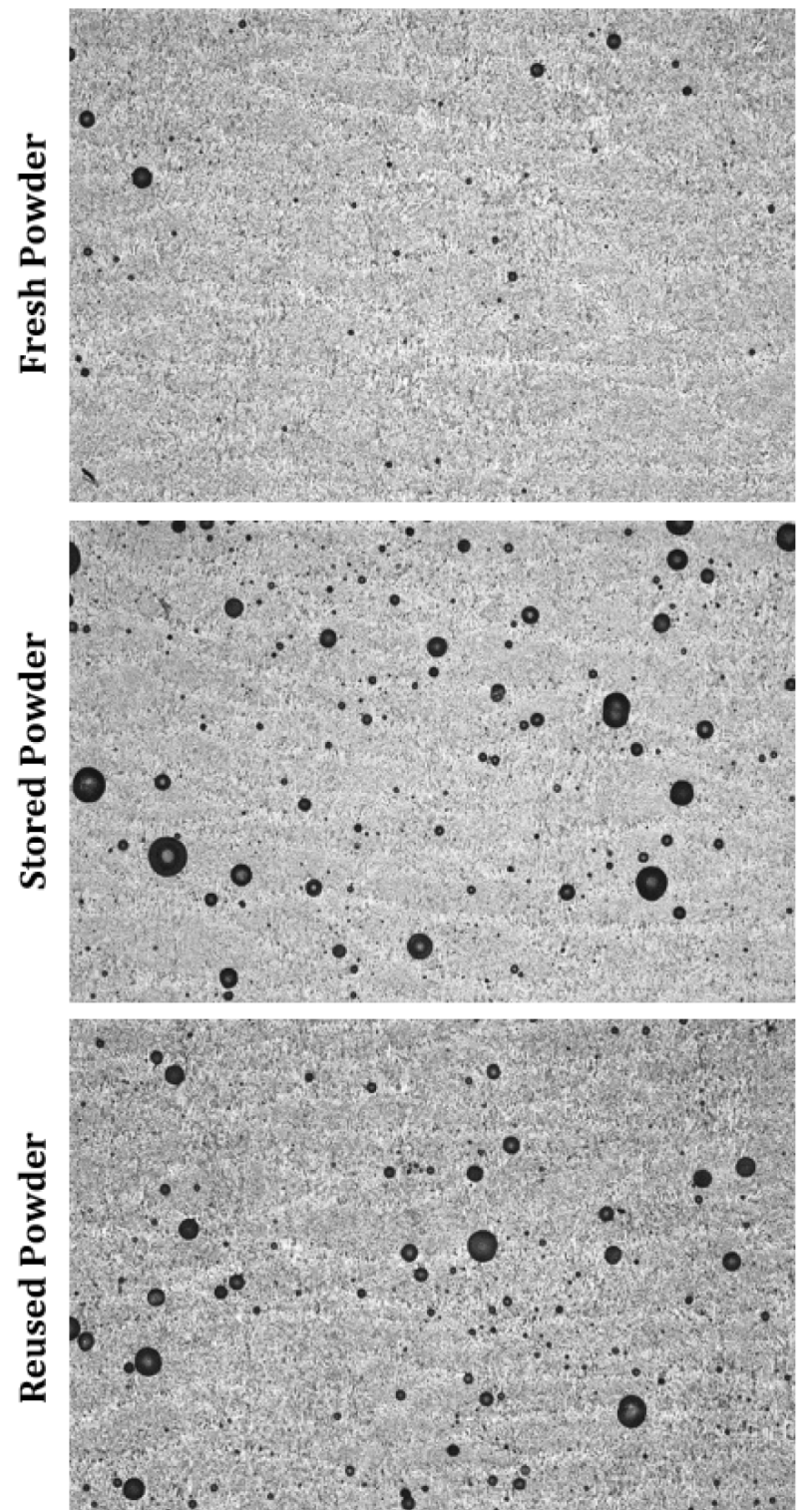

HIP
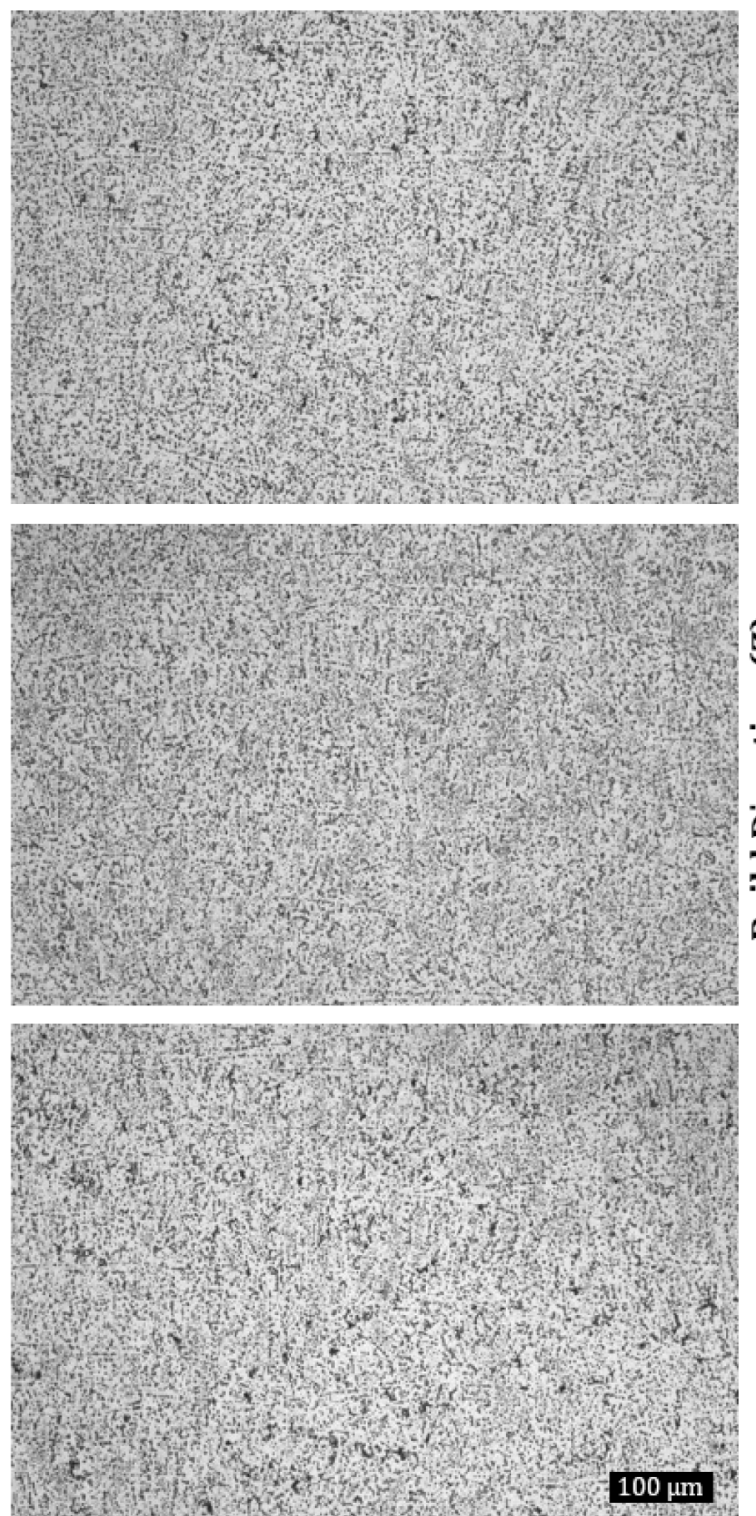

Fig. $2200 \times$ optical microscope images of tensile bars built with each powder type and heat treatment. Size and number of pores present in SRA samples depends on powder condition. No pores were present in HIP samples

were partially unloaded after bulk yielding to collect unloading modulus data. This occurred at a strain value of $1 \%$ for the SRA condition and $2.5 \%$ for the HIP condition. After unloading, the tension test was resumed to specimen failure.
Fracture surfaces were analyzed using a Carl Zeiss, Inc., GeminiSEM scanning electron microscope, a Carl Zeiss, Inc., LSM 800 laser confocal microscope and a Carl Zeiss, Inc., Axio Imager 2 optical imaging system to characterize porosity, surface crust, and to identify critical defects. 

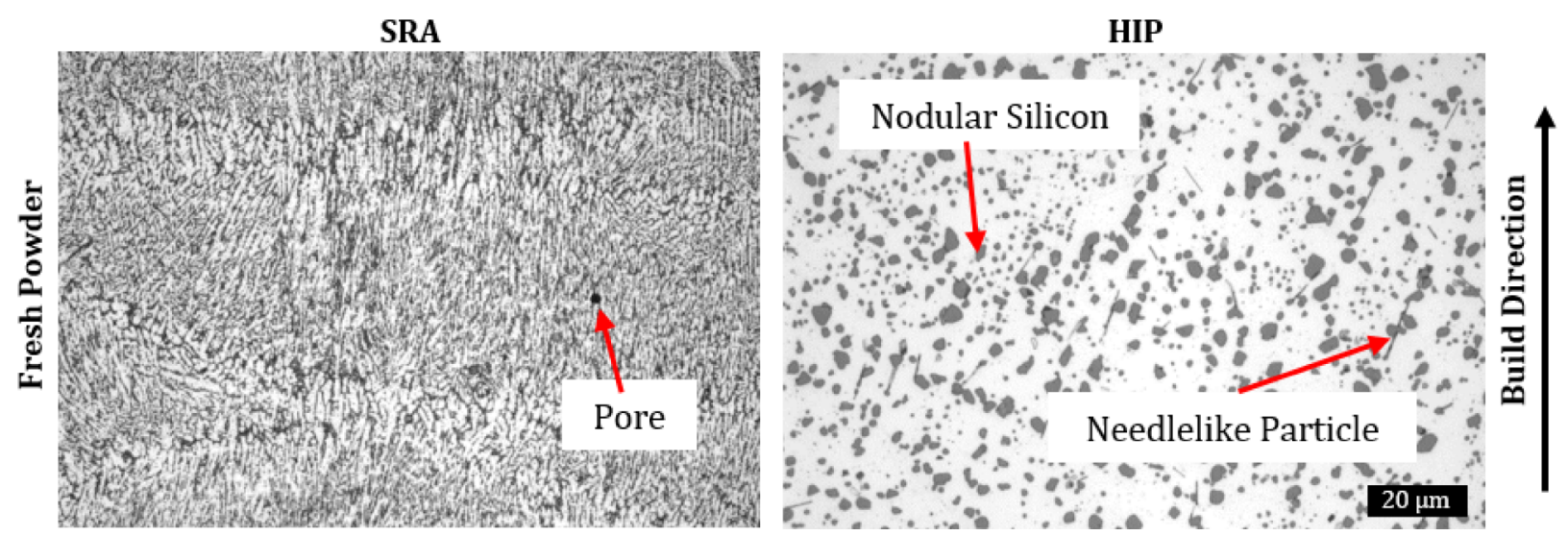

Fig. $31000 \times$ magnification optical microscope image of fresh powder microstructure in HIP and SRA condition. Significant coarsening of silicon precipitates is evident in HIP samples
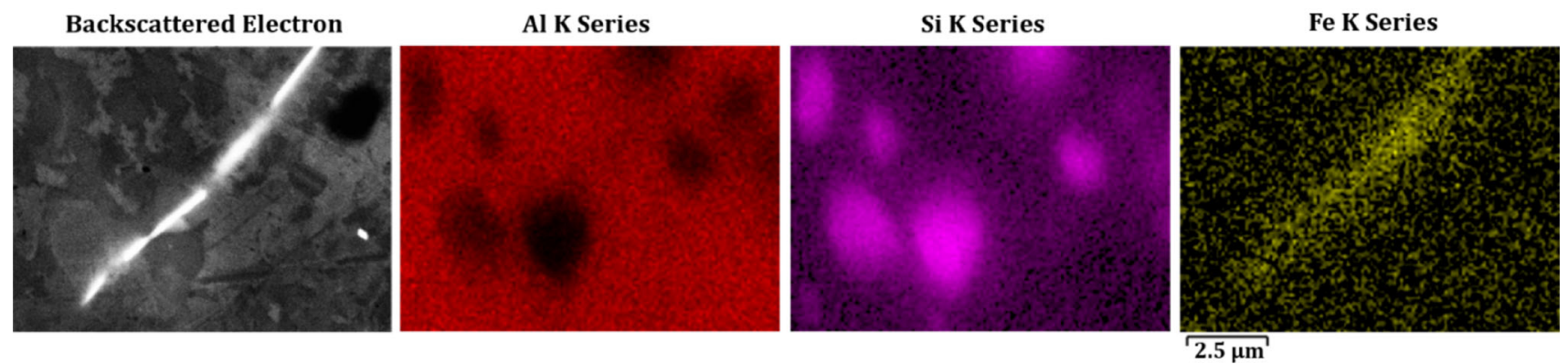

Fig. 4 Energy-dispersive spectroscopy image of aluminum matrix, nodular silicon, and iron-rich phase in the HIP condition. Nodular silicon and needlelike iron-rich particles were observed in all powder conditions

Laser scanning confocal microscope $z$-stacking techniques were used to determine the height of tensile fracture surfaces features.

Tensile samples were metallographically mounted and polished for optical microscope quantification of pore size distribution using Clemex Technologies, Inc., Vision PE software. Microstructures on cross sections were analyzed using electron backscatter diffraction (EBSD) and light optical microscope techniques using a Carl Zeiss, Inc., GeminiSEM scanning electron microscope and a Carl Zeiss, Inc., Axio Imager 2 optical microscope.

\section{Results and Discussion}

\section{Microstructure and Chemical Characterization}

Chemical composition of each powder determined by GDMS is shown in Table 1. No significant difference in composition was observed between each powder condition. Each powder contained approximately 88 wt. $\%$ aluminum, 11 wt. $\%$ silicon, and 0.3 wt.\% magnesium. Traces of iron, copper, and nickel were detected. Lighter elements (hydrogen, oxygen, and nitrogen) were detected using a
LECO $^{\circledR}$ ONH elemental analyzer, but results are unclear and not presented in this paper.

Medium magnification $(200 \times)$ optical microscope images of SRA tensile samples show non-equilibrium fine cellular microstructure consisting of silicon and magnesium enriched intercellular regions (Fig. 2). Coarsened microstructural features that indicate the overlap of laser melt passes are present. Microstructure in the HIP tensile samples consists of larger evenly dispersed equiaxed silicon precipitates in an uninterrupted aluminum matrix (shown in all images). In the HIP material, laser melt passes and gas pores are no longer evident on the interior of the specimens in each powder condition. At 1000x (Fig. 3), a needlelike second phase is evident in the HIP parts. SEM and energy-dispersive spectroscopy (EDS) analysis (Fig. 4) show the presence of iron in the needlelike phase and silicon in the more spherical phase. This corroborates work by Takata [20], who observed a $\beta$-AlFeSi needlelike phase associated with heat treat and precipitation temperatures between 400 and $540{ }^{\circ} \mathrm{C}$. The HIP process exposed the tensile samples to $521{ }^{\circ} \mathrm{C}$ for $2 \mathrm{~h}$, allowing for the growth of this phase.

Figure 5 shows a backscatter electron channeling contrast image of the SRA microstructure from reused powder. 
Grains are elongated along the build direction. Each grain is composed of columnar subgrains as seen by the white cell boundaries within the larger columnar grains. Gas pores are located both on grain boundaries and inside of grains. Figure 6 shows an EBSD inverse pole figure map for every powder condition for SRA and HIP parts. Each powder condition for SRA parts exhibits (001) texture oriented along the build direction. The pole figure maps show that pores are most common at the boundary between melt passes. For HIP parts, the texture is predominantly (001) in the $z$-build direction, with some coarsening along

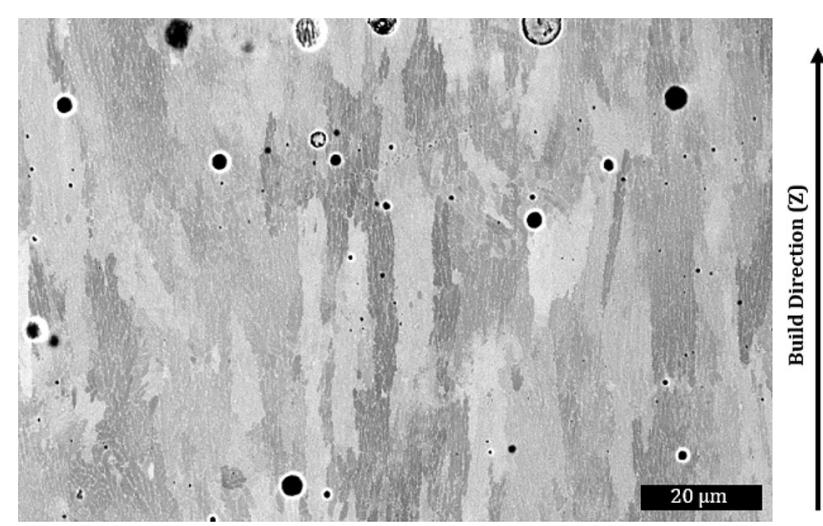

Fig. 5 Scanning electron microscope channeling contrast image of microstructure in SRA reused powder tensile sample. Grains, cellular subgrains and gas porosity are apparent. Gas pores are large relative to the size of microstructural features. Material contained on the interior of some pores (revealed as light gray) was determined by energy-dispersive spectroscopy to be adhered metallographic polishing compound other crystallographic orientations. Grain size analysis was performed using EBSD. Average grain width along the narrow axis is presented for each condition in Table 2 . Grains coarsened during HIP; the average grain width increased from 8.6 to $11.6 \mu \mathrm{m}$ in the fresh powder condition. Large distributions of grain sizes and extreme grain aspect ratios could convolute the interpretation of these measurements. Figure 7 presents EBSD pole figures for every powder condition for SRA and HIP parts. Pole figures suggest that HIP resulted in coarsening of (001), (010) and other orientations.

\section{Porosity}

The origin of pores is difficult to determine without close monitoring of the additive manufacturing solidification process. In this case, pores are identified based upon their morphology and interior surface finish. Spherical pores with melted and smooth interior surfaces are considered to be formed by gas contained in the melt pool. Elongated and jagged pores, often containing intact powder particles, are considered to be lack of fusion defects. Figures 5 and 6 show that gas pores present in the SRA condition are relatively large in comparison with microstructural features such as grains and subgrains. As a result, it is probable that these pores had a significant impact on the deformation mechanisms and mechanical properties of the tensile bars. Pores could reduce the strength of the material by providing a route of easy fracture [13]. These pores may be attributed to water uptake on the surface of the aluminum
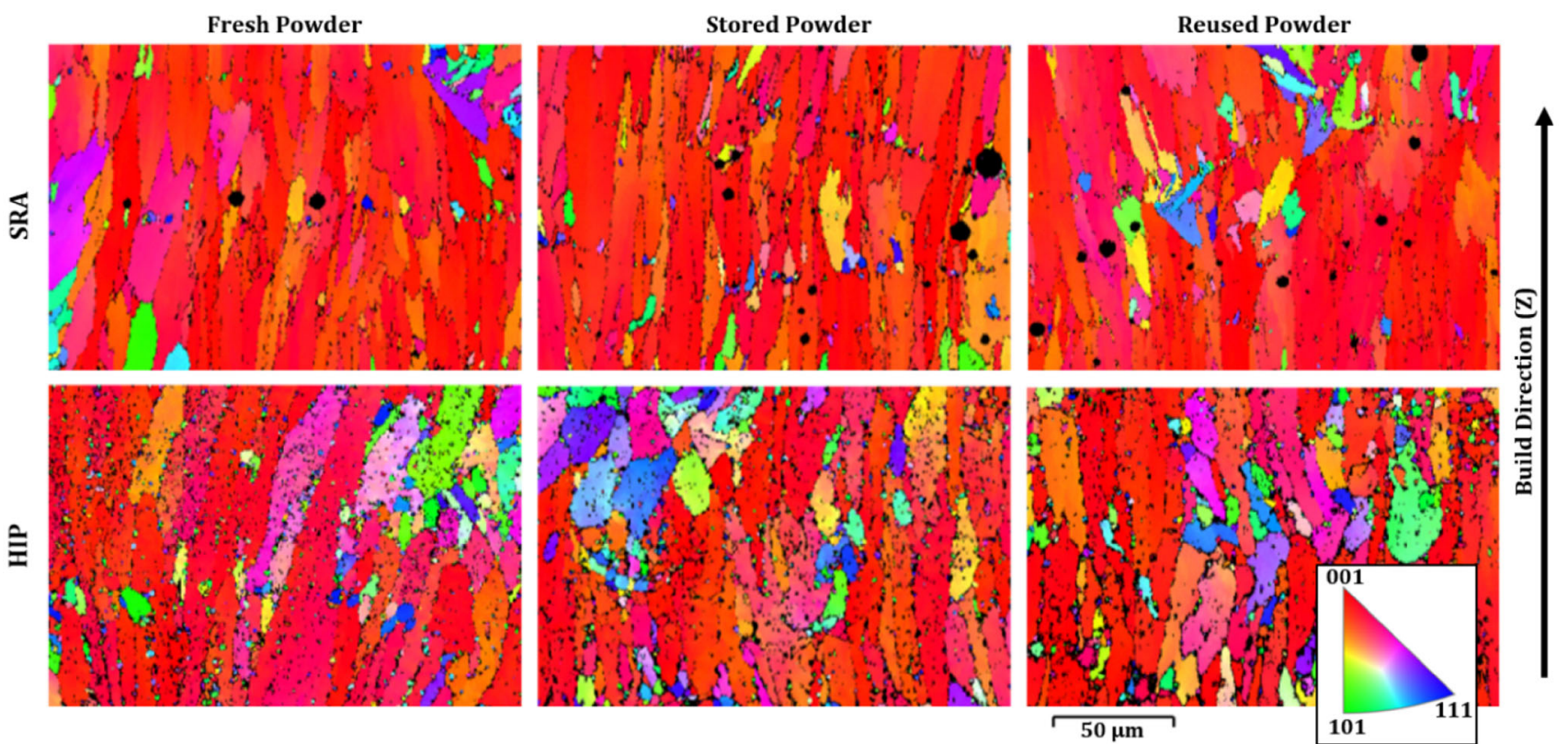

Fig. 6 Electron backscatter diffraction maps of Z-direction texture for each powder in SRA and HIP condition. The maps suggest significant [001] texture along the build direction 


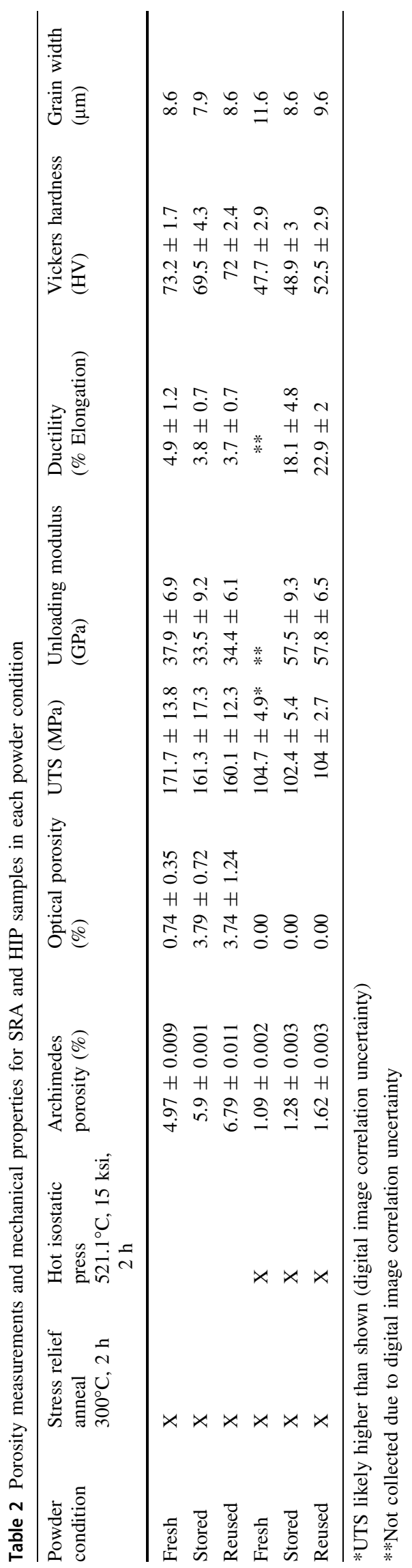

powder. Analysis of pore location suggests that pores lie preferentially at the boundaries between grains. However, pores were observed at the interior of grains in numerous cases. Many of the pores are on the order of the grain size so that this designation of boundary versus interior is difficult to make.

Table 2 shows density determined by optical microscopy and Archimedes density techniques. Optical microscope analysis suggests that in SRA parts, the interior porosity of the samples produced with fresh powder was less than $1 \%$, while the interior porosity of the samples produced with stored and reused powder was over $3 \%$. Optical microscopy of tension samples sectioned at multiple build heights showed that the pores were dispersed equally along the build height. HIP eliminated the interior porosity for all three powder conditions. The Archimedes density technique suggests porosity values higher than those measured directly from optical microscope images; the discrepancy between values may be due to the presence of a crust on the surface of the tensile bars. Figure 8 shows this crust in cross section, which presents as a series of small cracks on the surfaces of the parts. Cracks associated with the crust penetrated several hundred micrometers into the tensile specimens in all powder conditions. In most cases, HIP closed interior gas pores and reduced surface crust. However, some $150 \mu \mathrm{m}$ surface cracks were present in HIP samples due to the technique's inability to close surface pores (Fig. 9); this crust porosity remains on the order of $1 \%$ of the total sample volume. HIP is unable to close pores connected to the part surface because this surface connection allows internal and external pressure to equilibrate and reduce the squeezing force [22]. Many authors have reported inability to close surface porosity by HIP alone [23, 24]. Machining the parts surface to eliminate crust could improve apparent strength and ductility by removing stress concentrations from the part surface, but machining additive manufactured parts is usually not an appealing procedure. Closing surface porosity prior to HIP through mild abrasive blasting could lead to increased mechanical performance.

\section{Mechanical Properties}

Mower [25] showed that surface defects and spherical silicon particles negatively impacted fatigue performance in SLM AlSi10Mg. Mower also reported that as-printed SLM AlSi10Mg tensile samples exhibited low ductility (2.5\% elongation from one specimen presented) with no indication of necking when pulled along the build direction. Mechanical properties in this study are generally consistent with those reported by Mower. Table 2 shows the mean and standard deviation of mechanical properties for all three powder conditions and both heat treatments. It 

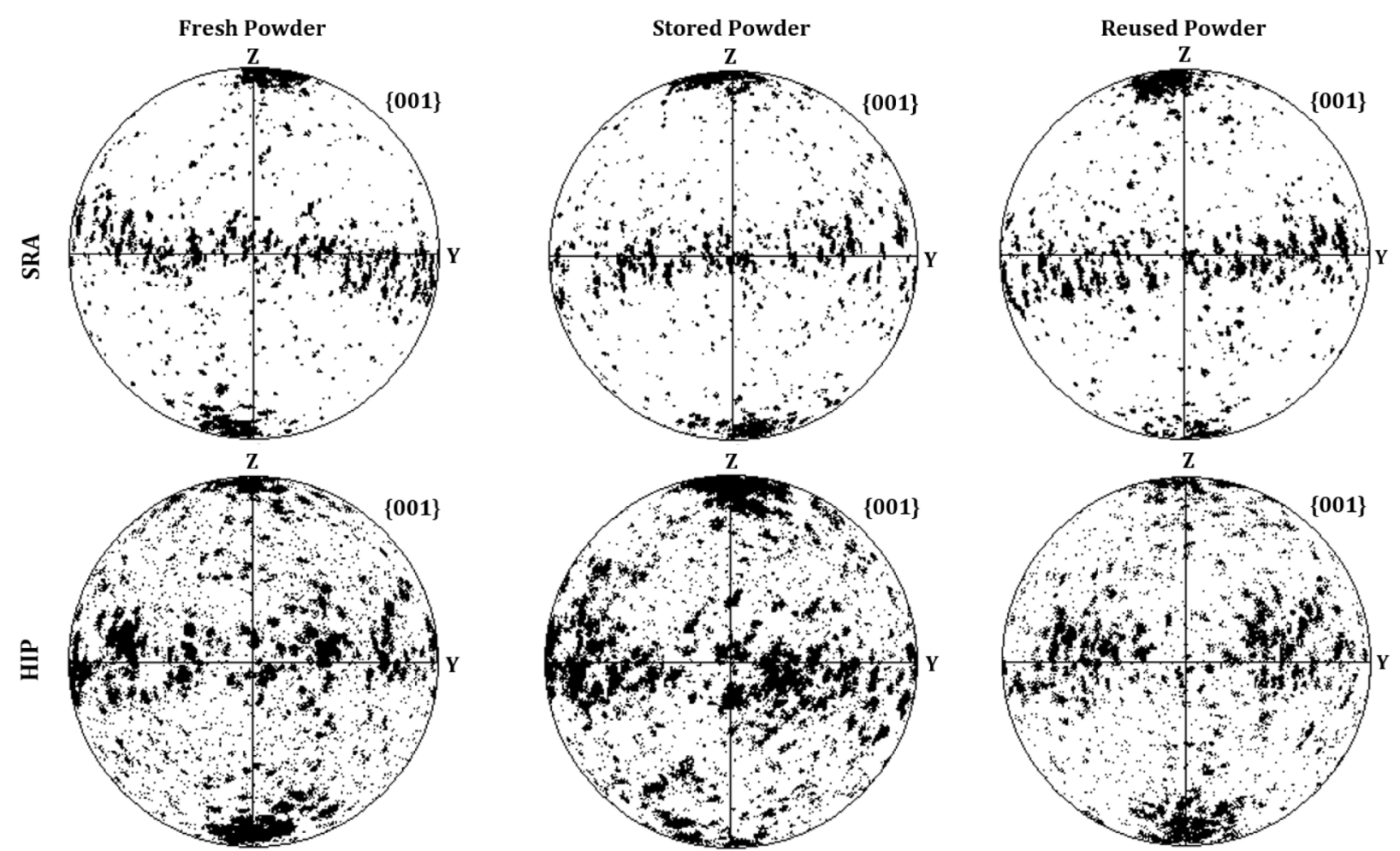

Fig. 7 Electron backscatter diffraction $\{001\}$ pole figures (001) texture is dominant in stress relief annealed samples. HIP after stress relief annealing resulted in coarsening of (100) and (010) orientations

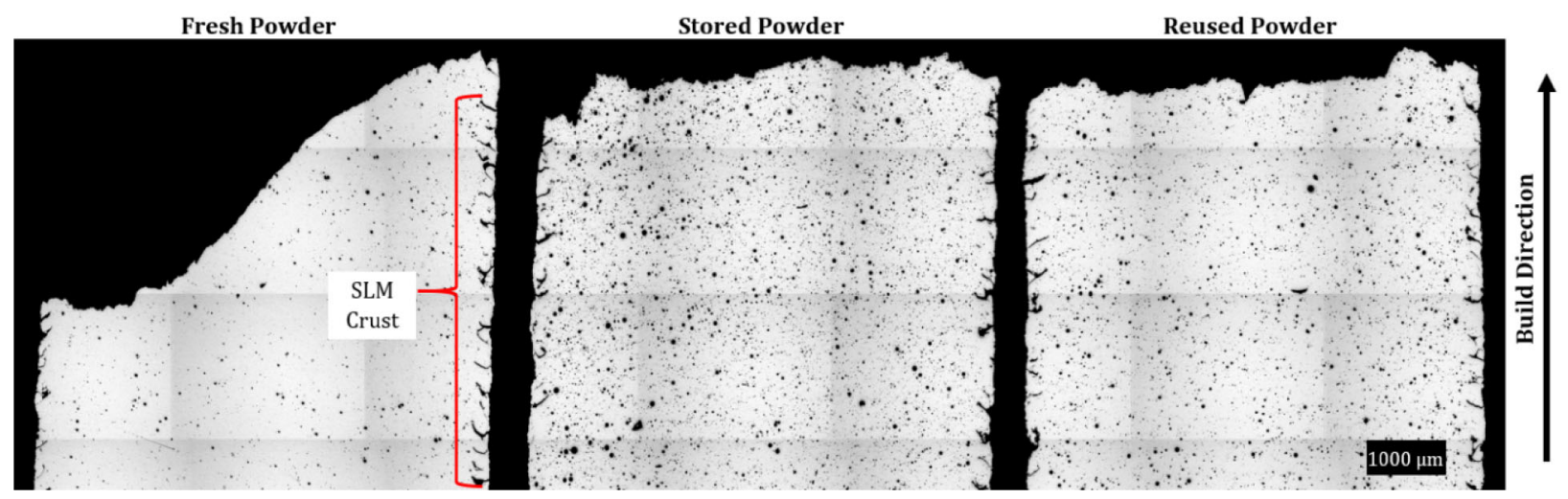

Fig. 8 Cross section of tensile bars built from all three powders indicates crust presence normal to the build direction prior to HIP

should be noted that these are apparent properties calculated from the cross section area of specimens measured by a micrometer and calipers. The inherent modulus and strength of the material are considerably higher if the cross section is corrected to account for porosity and surface defects. Specific aspects of the tensile data which are not apparent in the averaged data are explored using stressstrain curves in Figs. 10, 11, and 12. Each dataset is presented to elucidate the effect of a manufacturing parameter (powder condition, location on build plate, and thermal history) on mechanical performance.
Figure 10 shows the effect of powder condition on tensile performance. In the stress relieved condition, stored powder exhibited a lower ductility and strength than fresh powder. The relatively poor performance of the stored powder is attributed to higher internal porosity due to moisture uptake during storage. This result suggests that powder reuse may not be feasible in the AlSi10Mg system given the large reduction in ductility and strength. In has been suggested that this reduction in mechanical performance could be corrected by techniques such as powder bake-out [6] or by industrial techniques for reconditioning oxidized powder proposed by O'Neill [26]. The premise of 


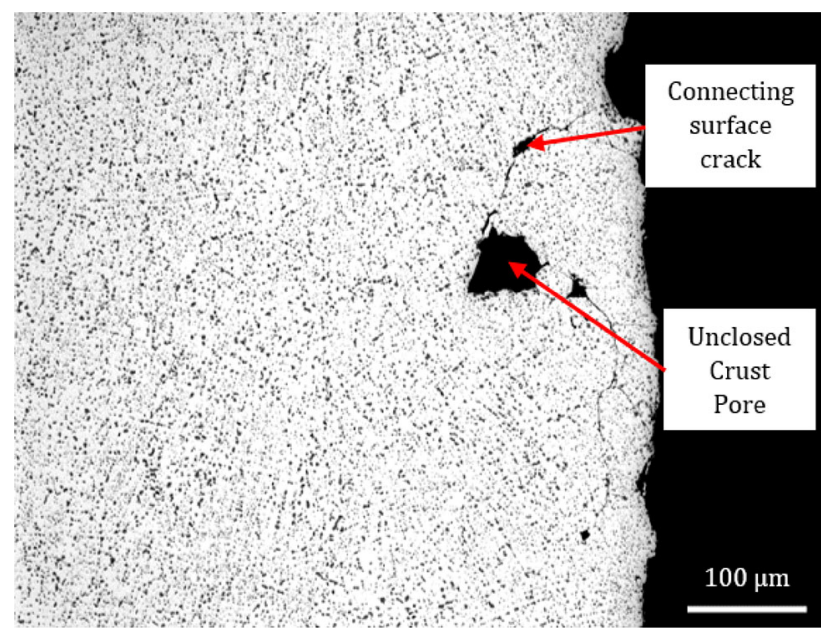

Fig. 9 An unclosed pore in tensile bar built with fresh powder after HIP. Surface cracks connect the pore to the surface these techniques is that by elevating the powder temperature prior to reuse, the adhered water on the powder surface is evaporated, leading to a reduction in porosity and an increase in strength and ductility.

Figure 11 shows the impact of location on the build plate on mechanical properties. The plot suggests that tensile specimens from one location (Location A) on the build plate exhibited consistently improved mechanical properties over another area (Location B) on the build plate. It is proposed that the root cause of this effect is related to argon flow direction and the direction of travel of the powder spreading blade. Location $\mathrm{A}$ is in the corner of the build where the argon flow and the powder spreading began, while location B is the opposite corner. Charactering the effects of powder spreading and inert gas flow on mechanical performance is one potential topic for the future work.
Fig. 10 Stress-strain plot for fresh and stored powder tensile bars in the stress relief annealed condition. Stored powder tended to exhibit lower ductility than fresh powder

Fig. 11 Stress-strain plot for tensile bars plotted with respect to location of the tensile bar on the build plate. Fresh, stored and reused tensile bars in the stress relief annealed condition are shown congruently. Location $\mathrm{A}$ is in the corner of the build where the argon flow and the powder spreading began, while location B is the opposite corner
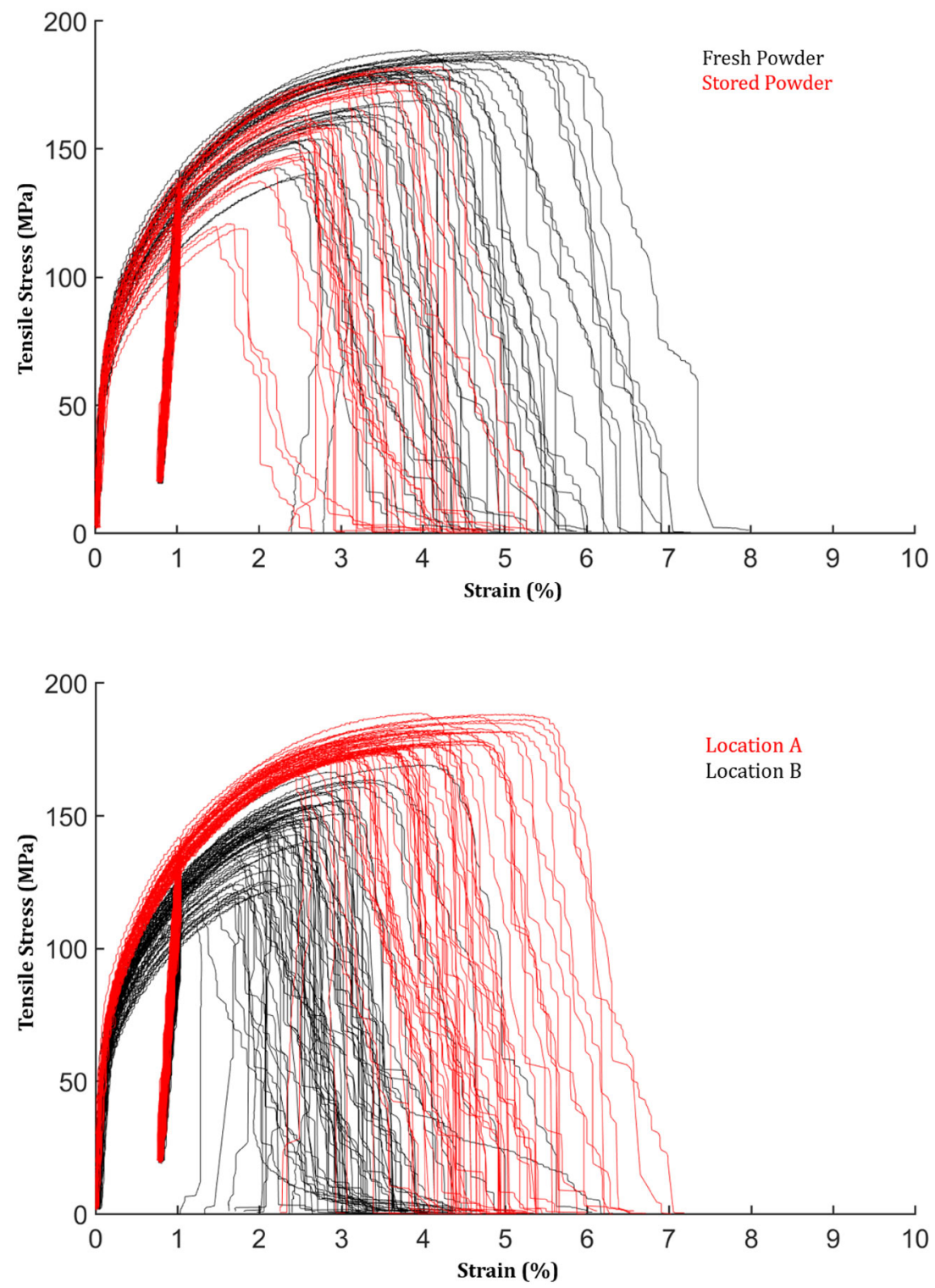
Fig. 12 Stress-strain plots for tensile bars built with various powders in both thermal processing conditions. HIP tended to decrease strength and increase ductility. Scatter in ductility after HIP is large

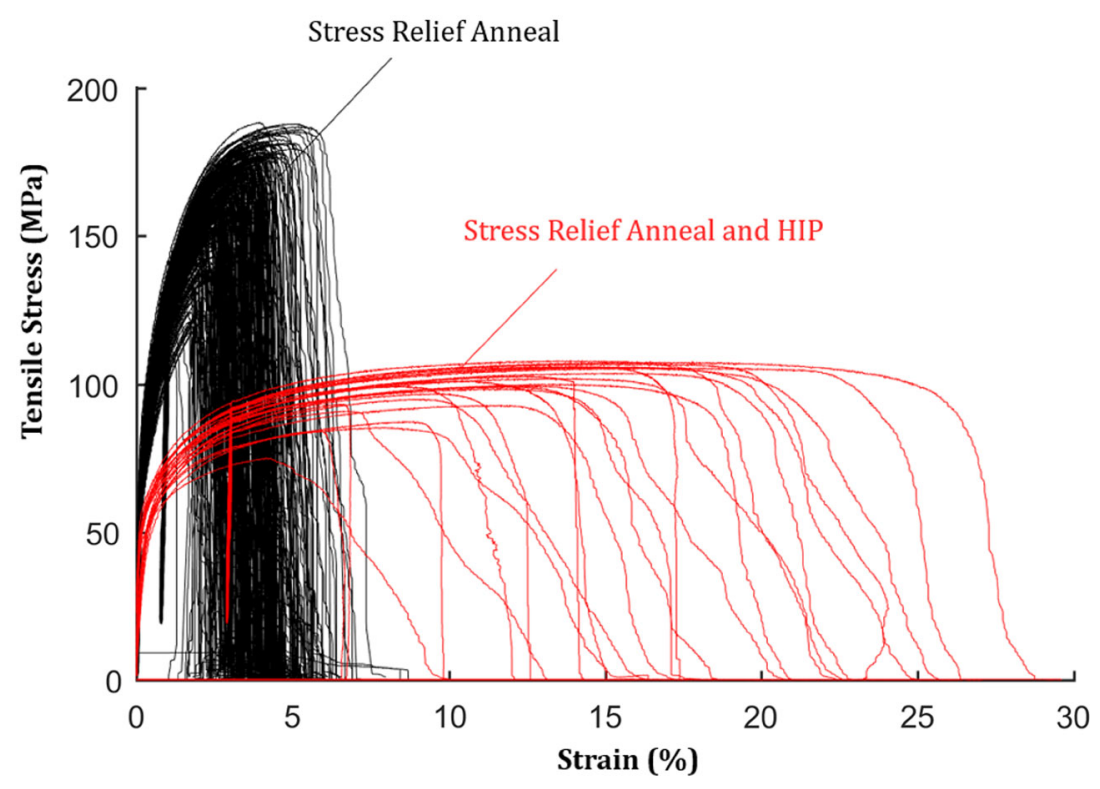

Fig. 13 Plot of ultimate tensile strength and elongation to failure suggests a positive correlation between ductility and strength in both thermal processing conditions

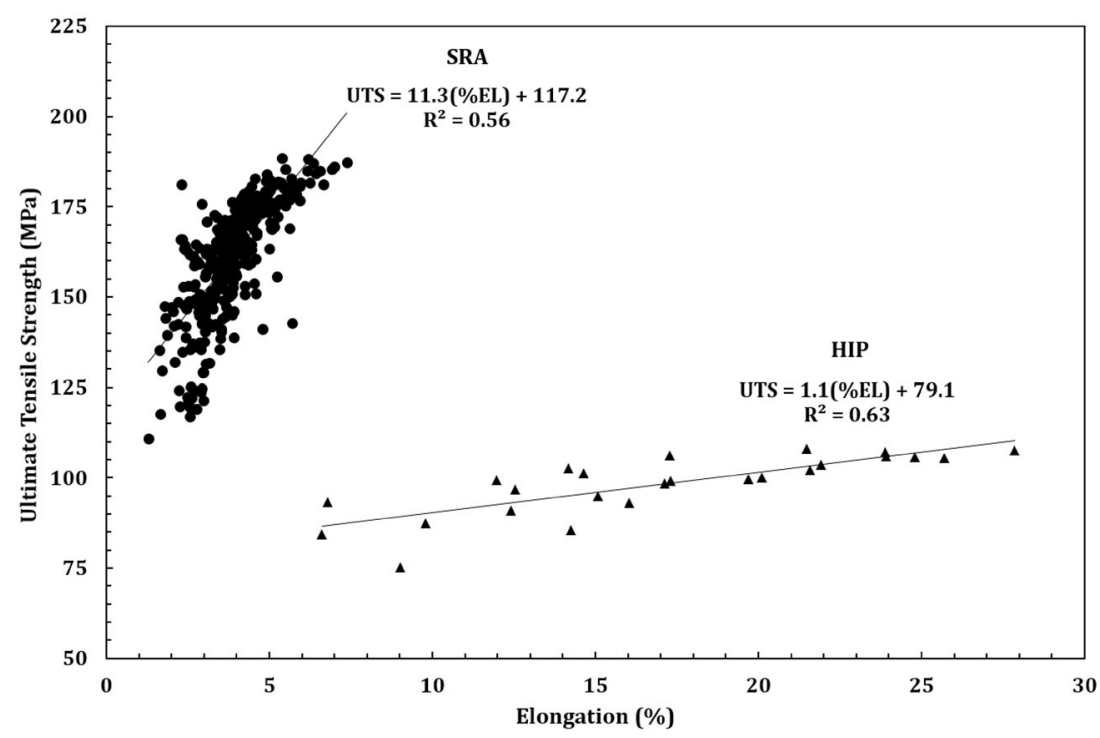

Figure 12 shows the effect of thermal processing on mechanical properties. SRA samples exhibited high strength of 160-170 MPa consistent with the fine-scale non-equilibrium microstructure, along with variable ductility of $2-7 \%$ elongation. This is attributed to the large amount of gas pores and surface crust in the SRA condition. HIP samples exhibited reduced strength of approximately $100 \mathrm{MPa}$. Reduction in strength after HIP is associated with microstructure coarsening and the absence of nanoprecipitates as reported by Yang [2]. HIP increased ductility by reducing voids associated with fast fracture. However, significant scatter in ductility between samples was observed with standard deviation of $4.8 \%$ elongation. In some lower threshold cases, HIP did not notably increase ductility in comparison with stress relieved samples. This raises a problem regarding the utility of HIP technique; if HIP cannot guarantee an increase in ductility, then it may not be justifiable to use the technique given the strength reduction and increased cost. If the surface crust is initiating low-ductility failure, then surface blasting the parts prior to HIP is one technique which could decrease scatter in ductility. It is important to note that the relatively small size of the tensile samples in this study could lead to divergence from strength and elongation values in comparable studies. The larger surface defect to bulk cross section ratio of tensile samples in this study could reduce ultimate tensile strength and ductility. Performing mechanical testing on larger parts could increase repeatability at the consequence of reducing the ability to detect weakest-link behavior. 
A positive correlation between ductility and ultimate tensile strength was observed in all thermal and powder conditions (Fig. 13). The observation is counterintuitive; typically, an increase in strength corresponds to a decrease in ductility and a decrease in strength corresponds to an increase in ductility. The fact that the trend exists in different magnitudes with different thermal histories further complicates explanation. The typical compromise between strength and ductility assumes that microstructure is the cause of differences in mechanical performance. Instead, in highly porous SLM samples, strength and ductility are likely determined by amount of surface crust, porosity, effective cross section of the tensile sample, and large flaws to initiate failure. Ultimately, these relationships suggest that defects facilitated deformation and fracture to different extents depending on thermal processing condition.

A comparable linear relationship was observed between the apparent unloading modulus and bulk porosity (Fig. 14). Increasing porosity in a sample from near zero to $8.4 \mathrm{vol} \%$ porosity led to an average decrease in the apparent unloading modulus from 63.0 to $23.4 \mathrm{GPa}$. This trend suggests that unloading modulus, in addition to ductility and ultimate tensile strength, could be used to estimate porosity in tensile specimens. The mechanism for this relationship is currently being studied. The reduction in effective cross section does not adequately account for such a large reduction in unloading modulus. One explanation is that during the strain prior to unloading modulus measurement, pores exhibited significant microplasticity due to cracking and deformation at the pore edge. This microplasticity led to a further reduction in the effective cross section and increased specimen compliance.

\section{Fracture Surface Analysis}

Optical fractography generally showed brittle failure with little plasticity or necking. Figure 15 presents a fractograph of a SRA fresh powder tensile specimen. No fibrous zone or shear lips are present on the fracture surface. Radial lines converge on the flat edge of the tensile bar, suggesting that a crack initiated at the surface and propagated on a plane normal to the tensile direction. It is proposed that fracture occurred due to mode I crack opening at the SLM

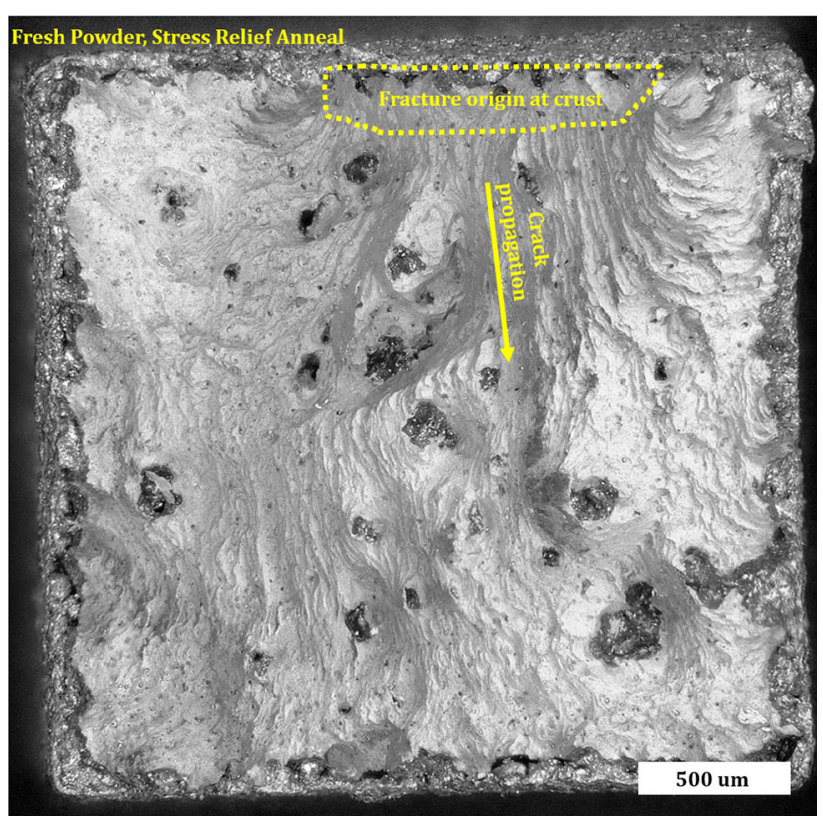

Fig. 15 Optical fractograph of a tensile specimen built with fresh powder in the SRA condition. The crack originated in the SLM crust and propagated across the specimen
Fig. 14 Unloading modulus as a function of bulk porosity. Unloading modulus in the wrought condition employs data reported by Mower [25]

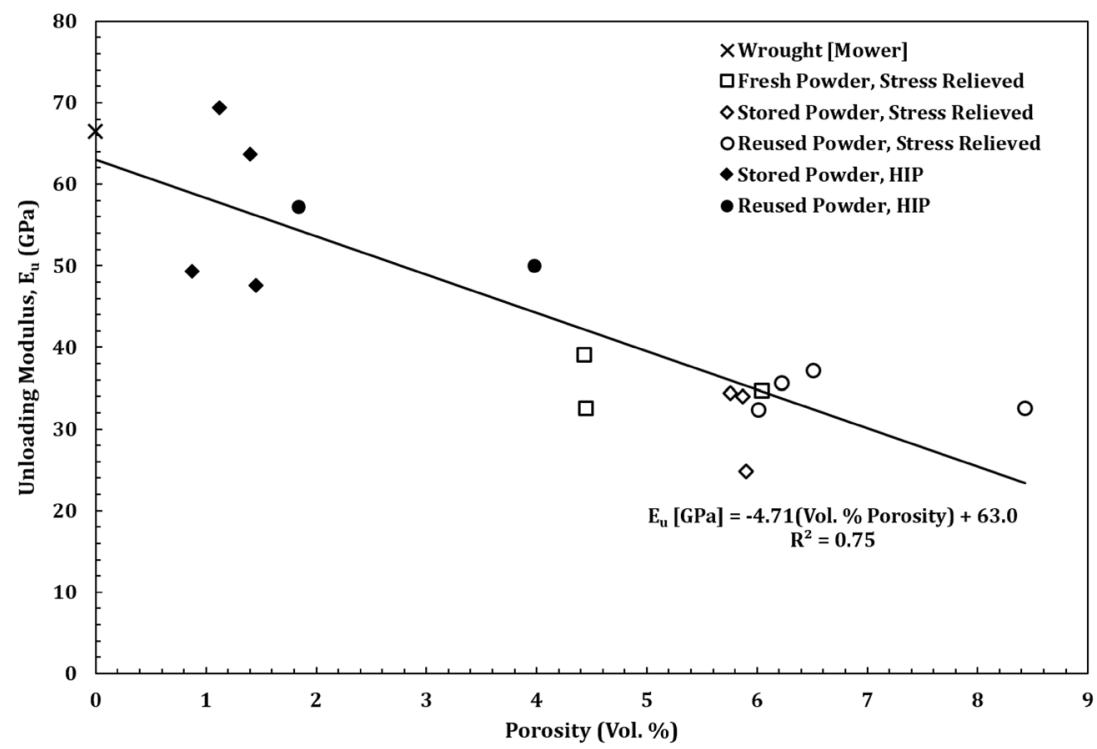


crust notch. $200 \mu \mathrm{m}$ lack of fusion pores are also visible on the fracture surface, suggesting that the crack propagated through a weakened region; this is corroborated by measurements of projected porosity on the fracture surface (4.53 vol\%), which were larger than the average internal porosity $(0.74$ vol\%). Other tensile specimens exhibited similar fracture surface features.

Figure 16 presents SEM images of the center of the fracture surfaces from each thermal and powder condition. Evidence of significant gas porosity is apparent on the fracture surface of each SRA specimen. After HIP, gas pores are no longer visible. Although little evidence of macroscopic plasticity was observed using optical fractographs, evidence of microvoid coalescence is certain with the presence of ductile dimples. Higher magnification SEM images show that ductile dimples were present on fracture surfaces with highly varying ductility in the HIP condition (Fig. 17). Samples exhibiting ductility of 6.6, 12.0, and $27.8 \%$ elongation had similar dimple morphology. This suggests that microscopic plasticity had
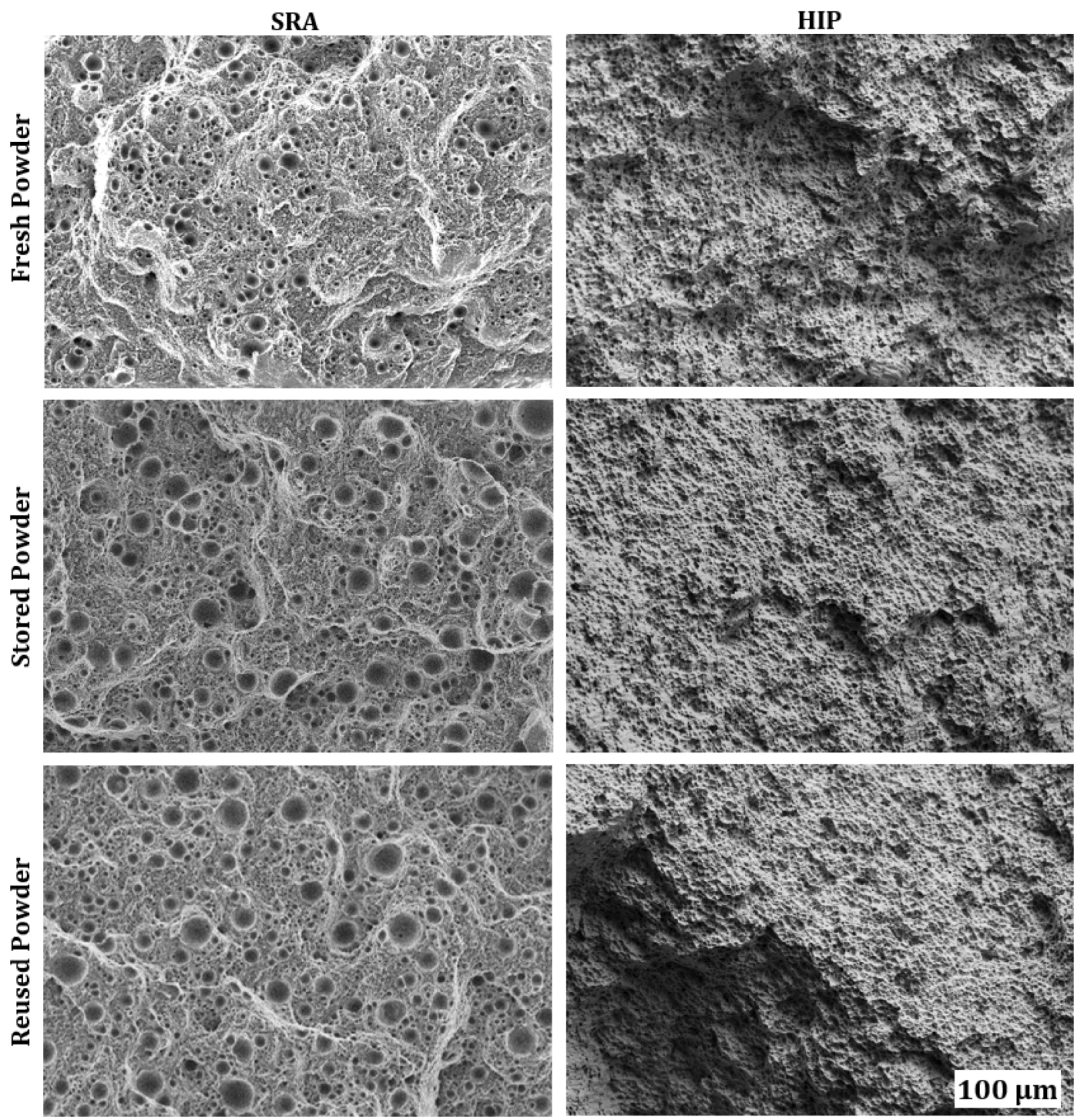

Fig. 16 SEM fractographs of tensile bars built with each powder type in SRA and HIP condition. Gas porosity is present on the fracture surface of each powder type prior to HIP 

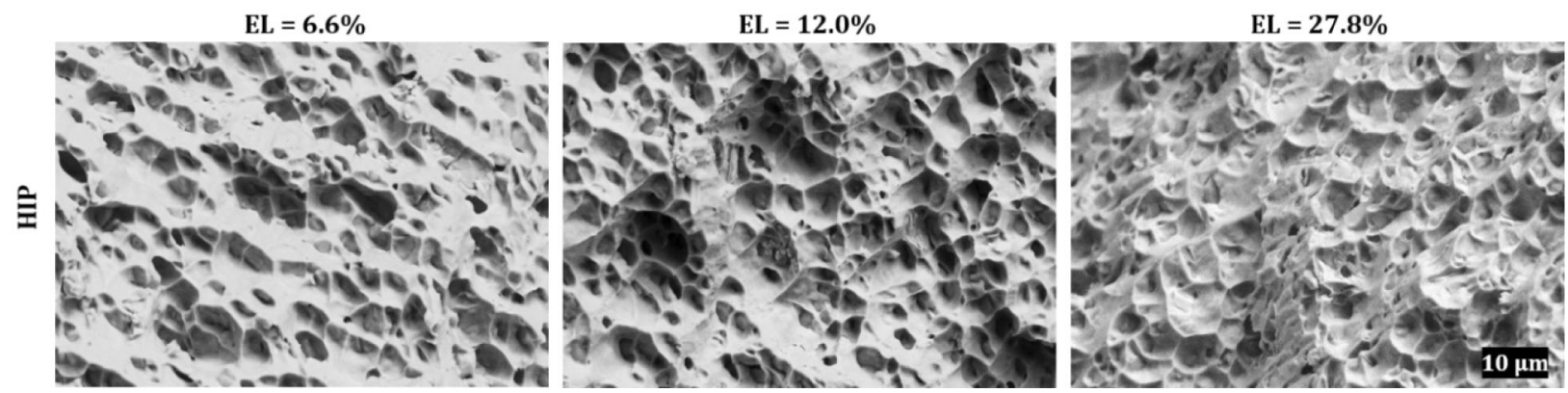

Fig. 17 SEM fractographs of HIP tensile bars exhibiting varying degrees of ductility. In all three cases, minimal necking was observed and ductile dimples associated with microvoid coalescence are apparent
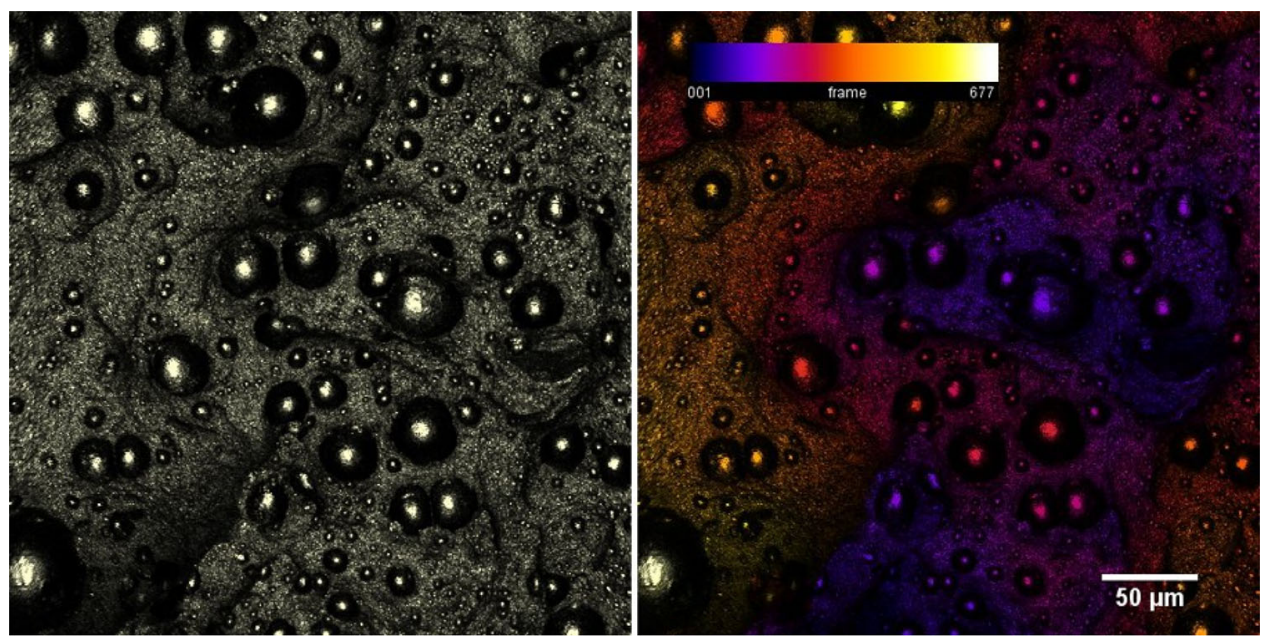

Fig. 18 Laser scanning microscopy (LSM) fractograph of a tensile bar built with fresh powder in SRA condition. Fracture surface topography analysis suggests that separation of the tensile bar occurred preferentially along pores

negligible impact on macroscopic ductility. As discussed previously, macroscopic ductility, in addition to strength and unloading modulus, was more likely determined by crust and pore size, resulting stress concentration, and effective load bearing cross section. Determining the effect of second phase particles is key to understanding whether mechanical performance was dictated by crust and pore size. However, the role of microstructure features such as silicon particles is unclear from SEM fractographs, which do not resolve the location of second phase particles in this case.

Figure 18 shows a $z$-stack laser scanning microscope fractograph of a stress relieved tensile sample. Composed of 677 stacked images separated by $0.25 \mu \mathrm{m}$ steps, information was gathered about the depth of pores and topography of the surface. After tensile failure, pores appeared to be elongated along the tensile axis to approximately twice their original diameter. Furthermore, pores tended to be split in two across their largest cross section. This observation suggests that fracture preferentially traveled across pores rather than through the bulk metal. This corroborates works which suggest that the tensile behavior of porous parts depends on local porosity, rather than the bulk porosity of the material [13].

\section{Conclusions}

Stress relieved and hot isostatic pressed samples of fresh, stored, and reused AlSi10Mg tensile specimens were characterized for microstructure, porosity, and mechanical properties. After stress relieving, all powder conditions exhibited predominantly (001) texture in the $z$-build direction. After hot isostatic pressing, all powder conditions exhibited coarsened (001) texture. Hot isostatic pressing removed all interior pores and reduced the size of surface crust laps.

Tensile performance for the stress relieved samples was superior in the fresh powder condition compared to stored or reused powder conditions. Stress relieved samples 
exhibited high strength and low ductility. In this condition, tensile behavior tended to be related to the number of pores on the fracture surface. HIP reduced the strength and generally increased the ductility. Scatter in ductility in the hot isostatic pressed condition was much higher than expected due to the dependence of ductility on effective cross section and retained surface crust laps.

These results suggest that use of fresh powder is imperative for optimal mechanical properties. Furthermore, HIP tends to increase mechanical performance, but the mechanism of failure is nonetheless heavily dependent on surface defects and requires additional stochastic characterization.

Acknowledgements The authors would like to acknowledge Brad Boyce and the Center for Integrated Nanotechnologies for their creation of the high throughout tensile testing system. Sara Dickens provided extensive scanning electron microscope fractography and electron backscatter diffraction microstructure analysis. Stephanie DeJong provided optical fractography. Alice Kilgo, Christina Profazi, and Chad Taylor provided metallography and porosity analysis. Donald Susan, Zahra Ghanbari, and Michael Heiden offered thoughtful peer reviews of the manuscript. This work was performed, in part, at the Center for Integrated Nanotechnologies, an Office of Science User Facility operated for the U.S. Department of Energy (DOE) Office of Science. Sandia National Laboratories is a multimission laboratory managed and operated by National Technology and Engineering Solutions of Sandia, LLC., a wholly owned subsidiary of Honeywell International, Inc., for the U.S. Department of Energy's National Nuclear Security Administration under Contract DE-NA-0003525.

\section{References}

1. K. Kempen, L. Thijs, J. Van Humbeeck, J.P. Kruth, Mechanical properties of $\mathrm{AlSi} 10 \mathrm{Mg}$ produced by selective laser melting. Phys. Proc. 39, 439-446 (2012)

2. P. Yang, M.A. Rodriguez, L. Deibler, B. Jared, J. Griego, A. Kilgo, A. Allen, D. Stefan, Effect of thermal annealing on microstructure evolution and mechanical behavior of an additive manufactured AlSi10Mg part. J. Mater. Res. (2018). https://doi. org/10.1557/jmr.2018.82

3. M.P. Tang, C.P. Pistorius, S. Narra, J.L. Beuth, Rapid solidification: selective laser melting of AlSi10Mg. J. Mater. 68(3), 960-966 (2016)

4. H. Matyja, B.C. Giessen, N.J. Grant, The effect of cooling rate on the dendrite spacing in splat-cooled aluminum alloys. J. Inst. Metals 196, 30-32 (1968)

5. N.T. Aboulkhair, N.M. Everitt, I. Ashcroft, C. Tuck, Reducing porosity in AlSi10Mg parts processed by selective laser melting. Addit. Manuf. 1(4), 77-86 (2014)

6. L. Deibler, B. Brown, C. Finfrock, J. Carroll, E. Coker, Effects of AlSi10Mg feedstock condition on part properties (Lecture), Annual International Solid Freeform Fabrication Symposium, Austin, TX, 2017

7. W.E. King, H.D. Barth, V.M. Castillo, G.F. Gallegos, J.W. Gibbs, D.E. Hahn, C. Kamath, A.M. Rubenchik, Observation of keyholemode laser melting in laser powder-bed fusion additive manufacturing. J. Mater. Process. Technol. 214, 2915-2925 (2014)
8. R. Cunningham, A. Nicolas, J. Madsen, E. Fodran, E. Anagnostou, M.D. Sangid, A.D. Rollett, Analyzing the effects of powder and post-processing on porosity and properties of electron beam melted Ti-6Al-4V. Mater. Res. Lett. 5(7), 516-525 (2017)

9. J.P. Harvey, P. Chartrand, Modeling the hydrogen solubility in liquid aluminum alloys. Metal. Mater. Trans. B 41B, 908-924 (2010)

10. C. Weingarten, D. Buchbinder, N. Pirch, W. Meiners, K. Wissenbach, R. Poprawe, Formation and reduction of hydrogen porosity during selective laser melting of AlSi10Mg. J. Mater. Process. Technol. 221, 112-120 (2015)

11. A.M. Gokhale, G.R. Patel, Origins of variability in the fracturerelated mechanical properties of a tilt-pour-permanent-mold cast Al-alloy. Scr. Mater. 52(3), 237-241 (2005)

12. A.M. Gokhale, G.R. Patel, Analysis of variability in tensile ductility of a semi-solid metal cast A356 Al-alloy. Mater. Sci. Eng. A 392(1-2), 184-190 (2005)

13. D.F. Susan, T.B. Crenshaw, J.S. Gearhart, The effects of casting porosity on the tensile behavior of investment cast 17-4PH stainless steel. J. Mater. Eng. Perform. 24(8), 2917-2924 (2015)

14. A.M. Gokhale, G.R. Patel, Quantitative fractographic analysis of variability in tensile ductility of a squeeze cast $\mathrm{Al}-\mathrm{Si}-\mathrm{Mg}$ base alloy. Mater. Charact. 54(1), 13-20 (2005)

15. C.J. Ruestes, E.M. Bringa, A. Stukowski, J.F. Rodriguez Nieva, Y. Tang, M.A. Meyers, Plastic deformation of a porous bec metal containing nanometer sized voids. Comput. Mater. Sci. 88, 92-102 (2014)

16. B.L. Boyce, A sequential tensile method for rapid characterization of extreme-value behavior in microfabricated materials. Exp. Mech. 50, 993-997 (2010)

17. B.L. Boyce, B.R. Salzbrenner, B.H. Jared, J.M. Rodelas, J.D. Madison, Rapid high-throughput mechanical evaluation of additively manufactured metals [Online] (2016). https://www.osti. gov/scitech/servlets/purl/1345092. Accessed 1 Dec 2017

18. B.C. Salzbrenner, J.M. Rodelas, J.D. Madison, B.H. Jared, L.P. Swiler, Y.-L. Shen, B.L. Boyce, High-throughput stochastic tensile performance of additively manufactured stainless steel. J. Mater. Process. Technol. 241, 1-12 (2017)

19. B.L. Boyce, B.C. Salzbrenner, J.M. Rodelas, L.P. Swiler, J.D. Madison, B.H. Jared, Y.-L. Shen, Extreme-value statistics reveal rare failure-critical defects in additive manufacturing. Adv. Eng. Mater. 19(8), 1-10 (2017)

20. N. Takata, H. Kodaira, K. Sekizawa, A. Suzuki, M. Kobashi, Change in microstructure of selectively laser melted AlSi10Mg alloy with heat treatments. Mater. Sci. Eng. A 704, 218-228 (2017)

21. LPW, Powder range-metal powders from LPW [Online] (2017). http://www.lpwtechnology.com/wp-content/uploads/2016/11/ LPW-Powders-Brochure-2017.pdf. Accessed 6 Nov 2017

22. M. Kireš, Archimedes' principle in action. Phys. Educ. 42(5), 6 (2007)

23. P.G. Bailey, W.H. Schweikert, HIP densification of castings. Acta Metal. 9, 451-462 (1976)

24. S. Tammas-Williams, P.J. Withers, P.B. Prangnell, The effectiveness of hot isostatic pressing for closing porosity in titanium parts manufactured by selective electron beam melting. Metal. Mater. Trans. A 47A, 1939-1946 (2016)

25. T.M. Mower, M.J. Long, Mechanical behavior of additive manufactured, powder-bed laser-fused materials. Mater. Sci. Eng. A 651, 198-213 (2016)

26. C.F. O'Niell, Method and apparatus for reconditioning oxidized powder. United States of America Patent U.S. 13/730,903, 3 July 2014 